\title{
Evaluation of Haptoglobin and Neutrophil Gelatinase Associated Lipocalin in Iraqi Patient with Type 2 Diabetic Nephropathy
}

\author{
Shakir Faris Tuleab Al-Aaraji and Sarah Mohammed Abd-Allah Al-Amri \\ Department of Chemistry, College of Education for Pure Sciences, University of Anbar.
}

\begin{abstract}
Diabetic Nephropathy (DN) is refereed as the kidney injury that occurs in individuals with diabetes, the earliest detectable change is the thickening in the glomerulus. The study objectives to estimate the diagnostic value plasma levels of Haptoglobin (HPt) and neutrophil gelatinase associated lipocalin (NGAL) as biomarkers for early disclosure of nephropathy in type 2 diabetic (T2D) patients. The present study was conducted on sixty T2D patients diagnosed beforehand, these patients were categorized into two equal groups according to their albumin/ creatinine ratio (ACR), including patients with normoalbuminuria (I) $(\mathrm{ACR}<30 \mathrm{mg} / \mathrm{g}$ Creatinine) and patients with microalbuminuria (II) (ACR=30-300 mg/g creatinine), twenty four healthy were chosen as a control group (III). Aspartate aminotransferase (AST), alanine aminotransferase (ALT), hemoglobin (Hb), U.Mic, U.Cr, ACR, HPt and NGAL were measured in the studied groups. NGAL \& HP were found to have a strong positive correlation with fasting plasma glucose (FPG), urine microalbuminuria (U.Mic), urine Creatinine (U.Cr) and (ACR). The present study reveals high significant differences between male and female diabetic patient groups in terms of $\mathrm{Hb}$.

In conclusion, a significant role for plasma NGAL and HPt in pathogenesis and progression of renal harm in DM, and a strongly positive correlated with the severity of proteinuria. This may be clinically useful variables for predicting the improvement of DN in the early stages of T2DM in the Iraqi population. [DOI: 10.22401/JNUS.20.2.02]
\end{abstract}

Keywords: Diabetic Nephropathy, Neutrophil gelatinase associated lipocalin, Haptoglobin, Type 2 Diabetes Mellitus.

\section{Introduction}

Diabetic nephropathy (DN) is the most significant microangiopathy of the complexities of diabetes characterized by raised urinary albumin secretion ratio, hypertension, and the decrease in the renal assignment prompting end-stage renal disease. As well, these patients have a high peril of cardiovascular sickness. Which further increments with worsening kidney function. ${ }^{[1]}$ $\mathrm{DN}$ is a quickly rising problem in the evolving countries with the epidemic of type 2 diabetes mellitus (T2DM). ${ }^{[2]}$ Presently, variations in albuminuria are viewed as a sign of onset or advancement of DN. Diabetic patients agonize from progressive renal pathological variations and the decrease of kidney function improvement, even if urinary albumin levels are in the normal ranges, suggest that albuminuria is not the ideal marker for the primary exposure of $\mathrm{DN}^{[3]}$

Tubulointerstitial and glomerular damage assumes a part in the pathogenesis of DN, some tubular hurts significances have been investigated for early discovery. ${ }^{[4]}$ From them is neutrophil gelatinase associated lipocalin (NGAL), which is created in epithelial cells and neutrophils. ${ }^{[5]}$ Former studies have demonstrated NGAL to be the most safely upregulated proteins in the renal tubules taking after ischemic harm, showing that it is a critical indicator for intense kidney damage. ${ }^{[6]}$ NGAL is a $25-\mathrm{kD}$ a molecule known to be hyper manufactured in kidney tubules within a few hours after harming experimental stimuli. Tubular excretion of NGAL associates with the acuteness of chronic kidney failure, as in autosomal dominant polycystic renal disease or glomerulonephritis. ${ }^{[7,8]}$ Haptoglobin is a hemoglobin-binding protein existing in the plasma. Its function is principal to control the destiny of hemoglobin out from red platelets after either extravascular or intravascular hemolysis. There are two current genotype at the HPt genetic locus signified 1 and 2. There are functional variations between the HPt 1 and HPt 2 proteins produce in the preserve against hemoglobin-driven oxidative stress that seems to have paramount clinical significance. Specifically, individuals with the 
HPt 2-2 genotypes and DM seem to be at safely greater peril of macrovascular and microvascular complexities. A strategy of managing high dose antioxidants, particularly to HPt 2-2 DM persons may be clinically active ${ }^{[9]} \mathrm{HPt}$ is a plasma glycoprotein and a positive intense stage protein that joins free hemoglobin, forming hemoglobin-haptoglobin (Hb-HPt) stable complex Hb-HPt complex extracted by macrophage by means of the cell-surface receptor (CD163). HPt avoids tissue destruction caused by free hemoglobin and lessens iron loss in hemolytic situations. HPt doings as a lymphocyte assignment and modulated the helper T-cell type 1 and type 2 (Th1/Th2) balance within the body. ${ }^{[10]}$

\section{Patients and Methods}

The present study was done in the National Diabetes Center for Treatment and Research at Al-Mustansiriya University between (February 2016-April 2016), our study included sixty T2D patients who were divided into two equal groups, group I, T2DM with norm albuminuria (albumin to Creatinine ratio [ACR] $<30 \mathrm{mg} / \mathrm{g}$ creatinine) and group II, T2DM with microalbuminuria (ACR $=30-300 \quad \mathrm{mg} / \mathrm{g}$ creatinine). The two diabetic groups were described according to urinary albumin secretion, their ages ranged within (36-65) years for both genders. The initial stage in examination of $\mathrm{DN}$ is to measure of urinary albumin in urine specimen in the morning. Several variables were examined to be compared with twenty four healthy controls (group III), such as body max index (BMI), thoracic to hip ratio $(\mathrm{T}-\mathrm{H})$, waist to hip ratio (W-H), Sys and Dia BP is coordinating with the diabetic patients who register in the study. The Urine specimens were collected from each individual into a sterile container and utilized for the measurement of urine microalbuminuria (U.Mic), urine Creatinine (U.Cr) and ACR. Venous blood specimens were collected from diabetic patients and controls into two sorts of vacutainer tubes as follows: first venous blood sample was collected in plain tube and left to clot for (30min) at room temperature and then centrifuge to separate at (3000rpm) for (10min) utilized for the biochemical examines. Second tube with EDTA, mixed gently by the shaker and then centrifuged to separate the plasma for $15 \mathrm{~min}$ at $1000 \mathrm{xg}\left(2-8 \mathrm{c}^{\circ}\right)$ within 30 min of accumulation and then transferred to a new polypropylene tube, plasma samples were stored at $-20^{\circ} \mathrm{C}$ until assayed. Fasting plasma glucose (FPG) level was determined according to a Trinder reaction by utilizing the glucose oxidase method, Cat. No. REF87409). Blood hemoglobin was measured according to the colorimetric method of drabkin's (Cat. No. REF1134015). ALT and AST levels were controlled by the utilizing of UV enzymatic technique (Cat. No. REF80027 and Cat. No. REF80025, respectively). Plasma NGAL and $\mathrm{HPt}$ were assessed using enzyme-linked Immunosorbent assay from the MyBiosource Company(Cat.No.\#MBS584559,Cat.No.\#MB7 02695, respectively).

\section{Statistical Analysis}

All information are expressed as means $\pm \mathrm{SD}$, unless stated otherwise. In all cases, $P<0.05$ was viewed significant (two-tailed). The relationships between NGAL and $\mathrm{HPt}$ with other laboratory variables were analyzed by two-sided Pearson relationship test. Data were put away and processed by utilizing a commercially obtainable (SPSS for Windows, Version 20.0).

\section{Results and Discussion}

Our outcomes showed no statistically significant differences in term of age, group $\mathbf{I}$ \& II showed a significant difference in BMI compared to group III $(P<0.05)$ Fig.(1) (A). Also, there were statistically significant differences in the terms W. Hip, W, Waist \& W. Thoracic between the normo and microalbuminuria diabetic groups (I \& II groups) in comparison to group III as given in Table (1), Fig.(1) (B, C, \& D respectively). The patients with norm-microalmuminuria group observed an important variation in the $\mathrm{W}-\mathrm{H}$ ratio and $\mathrm{W}-\mathrm{T}$ ratio. Higher Sys and Dia. BP levels were observed in I \& II compared to group III Fig.(1) (E \& F). The mean level of FPG was significantly higher $(P<0.05)$ in diabetic groups as compared to the group III Fig.(1) (G). 
Table (1)

Mean and standard deviation for Various biochemical Variables in control, Case of DM with DN and Case of DM without DN.

\begin{tabular}{|c|c|c|c|c|}
\hline \multicolumn{2}{|c|}{ Variables } & \multirow{2}{*}{$\begin{array}{c}\begin{array}{c}\text { Group I } \\
(\text { Mean } \pm \text { SD) }\end{array} \\
52.77 \pm 8.05^{\mathrm{a}}\end{array}$} & \multirow{2}{*}{\begin{tabular}{l||} 
Group II $($ Mean \pm SD $)$ \\
$52.93 \pm 7.77^{\mathrm{a}}$
\end{tabular}} & \multirow{2}{*}{$\begin{array}{c}\begin{array}{c}\text { Group III } \\
(\text { Mean } \pm \text { SD })\end{array} \\
52.08 \pm 9.21^{\mathrm{a}} \\
\end{array}$} \\
\hline Age & years & & & \\
\hline BMI & $\mathrm{kg} / \mathrm{m}^{2}$ & $28.50 \pm 3.82^{\mathrm{a}}$ & $29.02 \pm 3.75^{\mathrm{a}}$ & $23.69 \pm 2.29^{\mathbf{b}}$ \\
\hline W.hip & $\mathrm{cm}$ & $114.87 \pm 13.60^{\mathbf{b}}$ & $106.20 \pm 14.38^{\mathrm{a}}$ & $97.88 \pm 9.80^{\mathrm{c}}$ \\
\hline W.waist & $\mathrm{cm}$ & $108.07 \pm 9.88^{\mathrm{a}}$ & $101.03 \pm 17.66^{\mathrm{a}}$ & $85.00 \pm 11.04^{\mathbf{b}}$ \\
\hline W.thoracic & $\mathrm{cm}$ & $110.57 \pm 12.47^{\mathbf{b}}$ & $104.40 \pm 11.24^{\mathrm{a}}$ & $92.67 \pm 8.78^{\mathrm{c}}$ \\
\hline W-H ratio & $\mathrm{cm}$ & $108.07 \pm 9.88^{\mathrm{a}}$ & $101.03 \pm 17.66^{\mathrm{a}}$ & $85.00 \pm 11.04^{\mathrm{b}}$ \\
\hline W-T ratio & $\mathrm{cm}$ & $110.57 \pm 12.47^{\mathbf{b}}$ & $104.40 \pm 11.24^{\mathrm{a}}$ & $92.67 \pm 8.78^{\mathrm{c}}$ \\
\hline SBP & $\mathrm{mmHg}$ & $137.83 \pm 18.13^{\mathrm{a}}$ & $140.17 \pm 18.74^{\mathrm{a}}$ & $119.71 \pm 6.49^{b}$ \\
\hline DBP & $\mathrm{mmHg}$ & $82.97 \pm 8.00^{\mathrm{a}}$ & $86.20 \pm 11.59^{\mathrm{a}}$ & $72.54 \pm 5.33^{\mathrm{b}}$ \\
\hline Pulses & $\min ^{-1}$ & $81.70 \pm 11.18^{\mathrm{a}}$ & $82.40 \pm 12.91^{\mathrm{a}}$ & $73.42 \pm 3.66^{b}$ \\
\hline $\mathrm{Hb}$ & g/dl & $13.09 \pm 1.30^{\mathrm{a}}$ & $14.20 \pm 4.52^{\mathrm{a}}$ & $12.89 \pm 1.30^{\mathrm{a}}$ \\
\hline FPG & $\mathrm{mg} / \mathrm{dl}$ & $184.30 \pm 42.85^{\mathbf{b}}$ & $218.17 \pm 65.10^{\mathrm{a}}$ & $91.21 \pm 7.64^{\mathrm{c}}$ \\
\hline ALT & $\mathrm{U} / \mathrm{U}$ & $27.15 \pm 11.71^{\mathrm{a}}$ & $28.52 \pm 16.81^{\mathrm{a}}$ & $17.86 \pm 4.63^{\mathrm{b}}$ \\
\hline AST & $\mathrm{U} / \mathrm{l}$ & $29.59 \pm 15.27^{\mathrm{a}}$ & $28.90 \pm 10.80^{\mathrm{a}}$ & $25.59 \pm 4.90^{\mathrm{a}}$ \\
\hline U. Mic. & $\mathrm{mg} / \mathrm{L}$ & $12.67 \pm 6.92^{\mathrm{b}}$ & $117.67 \pm 55.69^{\mathrm{a}}$ & $13.33 \pm 7.61^{\mathrm{b}}$ \\
\hline U. Cr & $\mathrm{mmol} / \mathrm{L}$ & $9.85 \pm 4.76^{\mathrm{a}}$ & $9.01 \pm 6.84^{\mathrm{a}}$ & $11.03 \pm 4.54^{\mathrm{a}}$ \\
\hline$\overline{\mathrm{ACR}}$ & $\mathrm{mg} / \mathrm{mmol}$ & $1.34 \pm 0.05^{\mathbf{b}}$ & $17.39 \pm 9.95^{\mathrm{a}}$ & $1.25 \pm 0.44^{\mathrm{b}}$ \\
\hline NGAL & ng/ml & $38.99 \pm 4.22^{\mathbf{b}}$ & $60.75 \pm 15.23^{\mathrm{a}}$ & $25.58 \pm 5.25^{\mathbf{c}}$ \\
\hline $\mathrm{HPt}$ & $\mathrm{mg} / \mathrm{dl}$ & $109.07 \pm 40.56^{\mathbf{b}}$ & $183.47 \pm 24.42^{\mathrm{a}}$ & $34.05 \pm 6.21^{\mathrm{c}}$ \\
\hline \multicolumn{5}{|c|}{$\begin{array}{l}\text { Notes: Similar letters mean no significant difference between the groups at a level of less } \\
\text { than } \mathbf{0 . 0 5} \text {, and various letters mean the existence of a significant difference at a } \\
\text { level of less than } \mathbf{0 . 0 5} \text {. }\end{array}$} \\
\hline
\end{tabular}
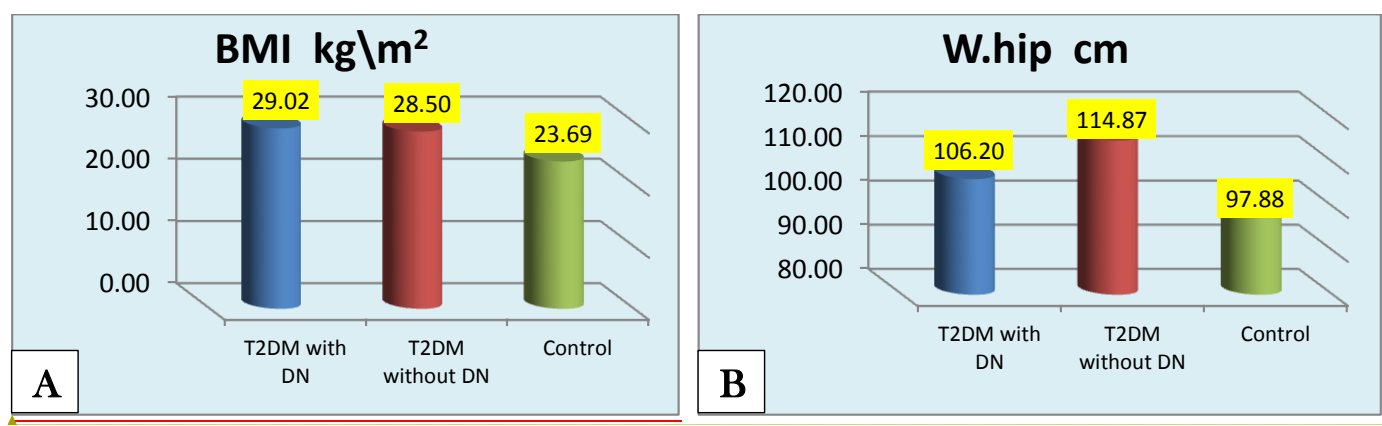

Formatted: Font: (Default) +Headings CS (Times New Roman), Complex

Script Font: +Headings CS (Times New Roman)
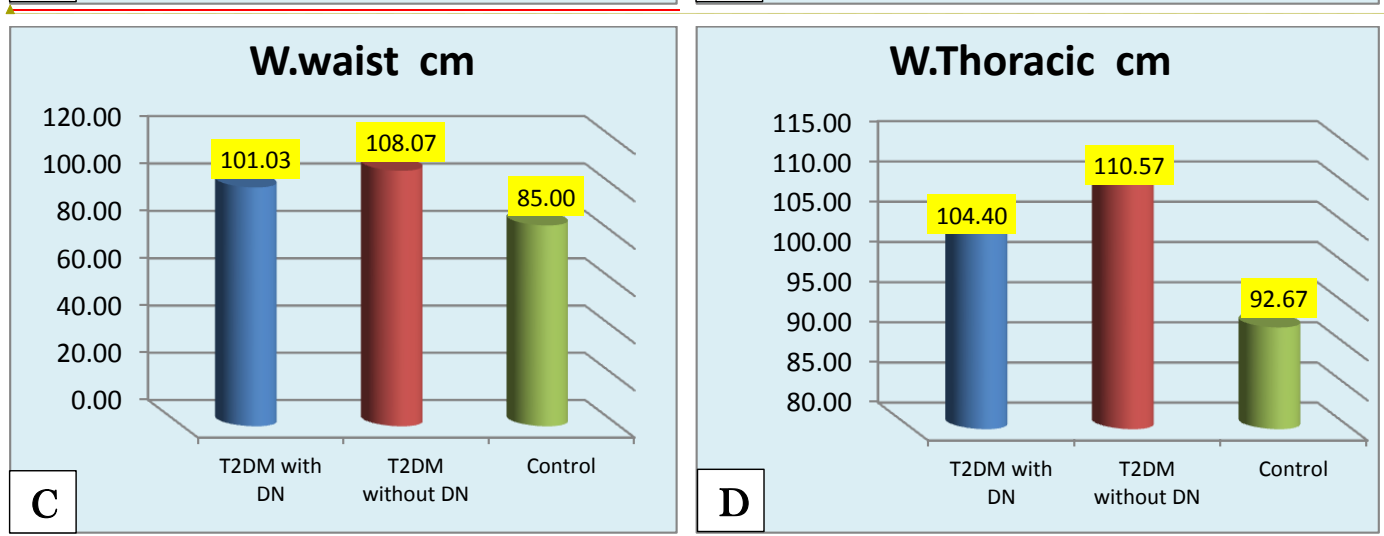
Shakir Faris Tuleab Al-Aaraji
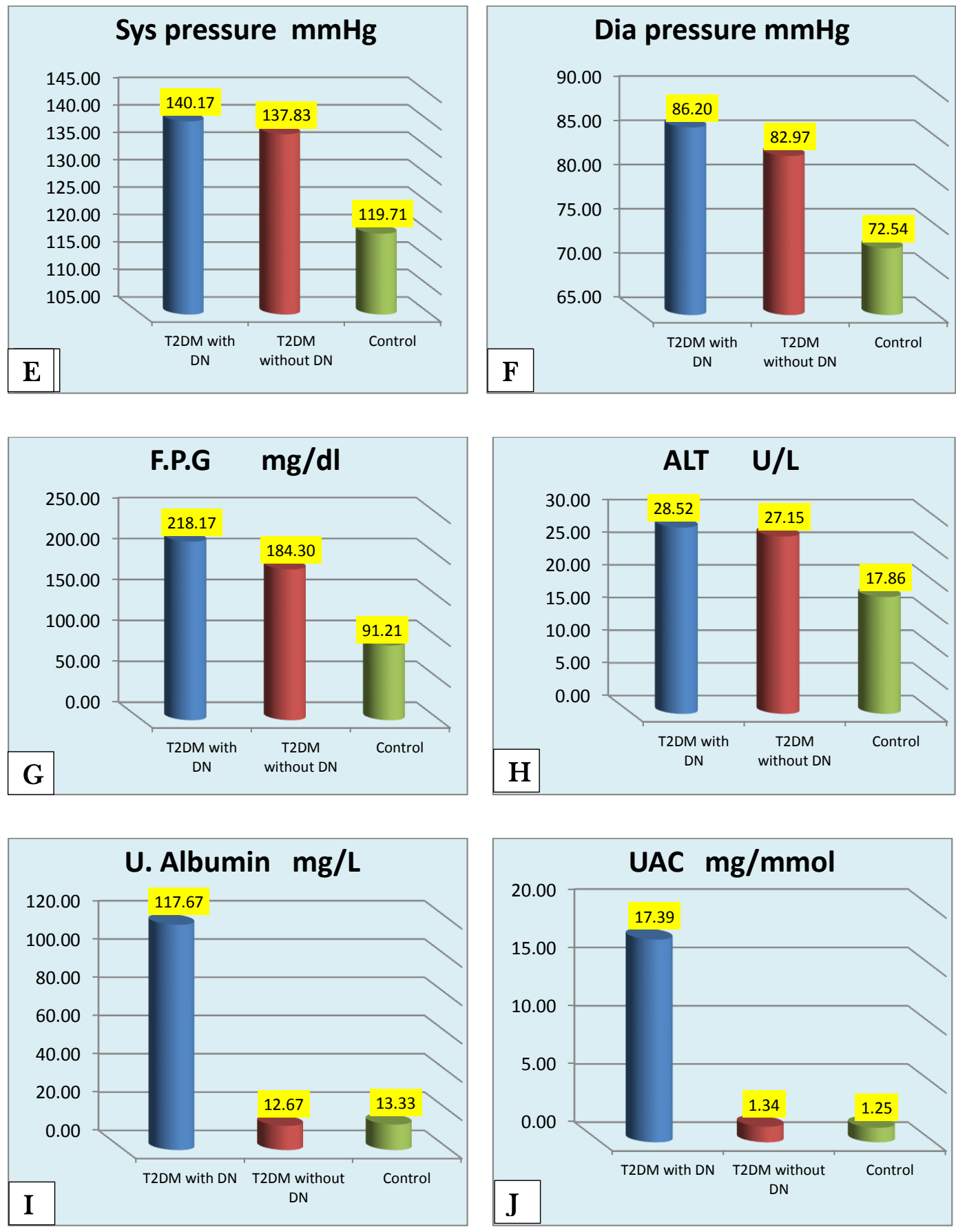

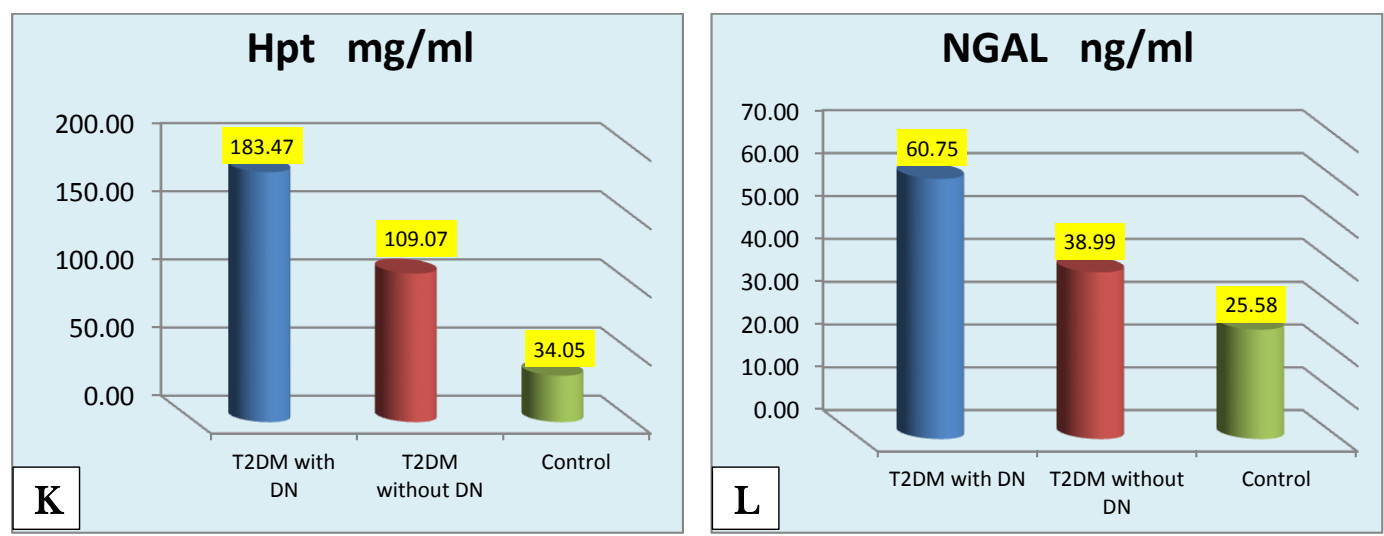

Fig.(1): Comparison between different in biochemical parameters studied groups.

Table (2)

Significant relationships between NGAL and HPt with other biochemical factors in diabetic patients with nephropathy.

\begin{tabular}{||c|c|c|}
\hline Variables & R & P \\
\hline \hline NGAL-BMI & 0.399 & $<0.01$ \\
\hline \hline NGAL-Sys PB & 0.412 & $<0.01$ \\
\hline \hline NGAL-Dia PB & 0.473 & $<0.01$ \\
\hline NGAL-Hb & 0.315 & $<0.01$ \\
\hline NGAL-FPG & 0.618 & $<0.01$ \\
\hline \hline NGAL-U.Albumin & 0.655 & $<0.01$ \\
\hline NGAL-UAC & 0.638 & $<0.01$ \\
\hline HPt-BMI & 0.420 & $<0.01$ \\
\hline \hline HPt-Sys PB & 0.444 & $<0.01$ \\
\hline HPt-Dia PB & 0.482 & $<0.01$ \\
\hline HPt-W.waist & 0.323 & $<0.05$ \\
\hline HPt-ALT & 0.326 & $<0.01$ \\
\hline \hline HPt-FPG & 0.631 & $<0.01$ \\
\hline HPT-U.Albumin & 0.695 & $<0.01$ \\
\hline HPt-ACR & 0.606 & $<0.01$ \\
\hline
\end{tabular}

The statistical analysis of outcomes demonstrated that there no significant differences in $\mathrm{Hb}$ and $\mathrm{U}$. $\mathrm{Cr}$ between the examined groups. Furthermore the ALT level was safely variations in diabetic groups than that in the control group, as shown in Table (1) Fig.(1) (H). Interestingly, the result shows that serum AST was not significantly different in the studied groups. Urinary-Mic and ACR were significantly increment in diabetic groups compared to group III and pronounced increment in the II group, Fig.(1) (I \& J). Plasma concentration of NGAL and HPt were significantly higher in patients with and without DN groups compared to a healthy group III, Fig.(1) ( $\mathrm{K} \& \mathrm{~L})$, indicating that plasma NGAL and HPt are risk factors of microangiopathy in patients T2DM. There were significant positive relationship between plasma NGAL with BMI, Sys. PB, Dia. PB and $\mathrm{Hb}$ as shown in Table (2). The Pearson correlation test showed a strong positive correlation between plasma NGAL with FPG, U. albumin, UAC and plasma HPt, as shown in Table(2) Fig.(2) and (3). In additional, there were significant positive correlations between plasma HPt with BMI, Sys. PB, Dia. PB, W. Waist, and ALT and a strong positive correlation with FPG, U. albumin, ACR and plasma NGAL, as shown in Table (2) Fig.(4) and (5). The diabetic patients with normoalbuminuria showed a significant difference between male and female in terms of BMI, W. waist, W. thoracic, and pulses, interestingly, the diabetic patients without DN and control group demonstrated a significant difference between male and female in $\mathrm{Hb}$, as appeared in Table (3). 
Shakir Faris Tuleab Al-Aaraji

Table (3)

The demographic and Anthropometric data of Diabetic Patients According to Gender.

\begin{tabular}{|c|c|c|c|c|c|c|}
\hline Variabl & & Factor & Sex & Mean \pm SD & T. Test & Sig \\
\hline \multirow{6}{*}{ BMI } & \multirow{6}{*}{$\mathrm{kg} / \mathrm{m}^{2}$} & \multirow{2}{*}{ Group I } & $\mathrm{M}$ & $29.51 \pm 4.04$ & \multirow{2}{*}{2.003} & \multirow{2}{*}{0.055} \\
\hline & & & $\mathrm{F}$ & $26.75 \pm 2.78$ & & \\
\hline & & \multirow{2}{*}{ Group II } & $\mathrm{M}$ & $30.04 \pm 3.40$ & \multirow{2}{*}{1.525} & \multirow{2}{*}{0.139} \\
\hline & & & $\mathrm{F}$ & $28.00 \pm 3.92$ & & \\
\hline & & \multirow{2}{*}{ Group III } & $\overline{\mathrm{M}}$ & $22.49 \pm 2.20$ & \multirow{2}{*}{-3.362} & \multirow{2}{*}{0.003} \\
\hline & & & $\mathrm{F}$ & $25.12 \pm 1.48$ & & \\
\hline \multirow{6}{*}{ W. waist } & \multirow{6}{*}{$\mathrm{cm}$} & \multirow{2}{*}{ Group I } & $\mathrm{M}$ & $111.16 \pm 8.92$ & \multirow{2}{*}{2.436} & \multirow{2}{*}{0.021} \\
\hline & & & $\mathrm{F}$ & $102.73 \pm 9.51$ & & \\
\hline & & \multirow{2}{*}{ Group II } & $\overline{\mathrm{M}}$ & $102.60 \pm 18.32$ & \multirow{2}{*}{0.479} & \multirow{2}{*}{0.635} \\
\hline & & & $\mathrm{F}$ & $99.47 \pm 17.48$ & & \\
\hline & & \multirow{2}{*}{ Group III } & $\bar{M}$ & $82.62 \pm 11.90$ & \multirow{2}{*}{-1.159} & \multirow{2}{*}{0.259} \\
\hline & & & $\mathrm{F}$ & $87.82 \pm 9.71$ & & \\
\hline \multirow{6}{*}{ W. thoracic } & \multirow{6}{*}{$\mathrm{cm}$} & \multirow{2}{*}{ Group I } & $\overline{\mathrm{M}}$ & $114.00 \pm 13.69$ & \multirow{2}{*}{2.095} & \multirow{2}{*}{0.045} \\
\hline & & & $\mathrm{F}$ & $104.64 \pm 7.23$ & & \\
\hline & & \multirow{2}{*}{ Group II } & $\mathrm{M}$ & $107.60 \pm 7.81$ & \multirow{2}{*}{1.601} & \multirow{2}{*}{0.121} \\
\hline & & & $\mathrm{F}$ & $101.20 \pm 13.37$ & & \\
\hline & & Croun $\mathrm{H}$ & $\overline{\mathrm{M}}$ & $90.31 \pm 10.14$ & 1466 & 0157 \\
\hline & & Group III & $\mathrm{F}$ & $95.45 \pm 6.17$ & -1.400 & $0.15 \%$ \\
\hline & & & $\mathrm{M}$ & $78.37 \pm 9.43$ & 208 & 0020 \\
\hline & & Group 1 & $\mathrm{~F}$ & $87.45 \pm 12.04$ & -2.298 & 0.029 \\
\hline Pulses & $\min _{-}^{1}$ & Groun II & $\overline{\mathrm{M}}$ & $82.87 \pm 14.94$ & 0195 & \\
\hline Puises & & & $\mathrm{F}$ & $81.93 \pm 11.03$ & 0.195 & 0.847 \\
\hline & & & $\mathrm{M}$ & $73.31 \pm 5.75$ & & \\
\hline & & Group III & $\mathrm{F}$ & $73.55 \pm 4.91$ & -.155 & $0.8 / 8$ \\
\hline & & Croun & $\overline{\mathrm{M}}$ & $13.64 \pm 1.23$ & 2176 & 0038 \\
\hline & & Group 1 & $\mathrm{~F}$ & $12.45 \pm 1.20$ & 2.170 & 0.050 \\
\hline $\mathrm{Hh}$ & dl & Croun II & $\bar{M}$ & $15.73 \pm 6.02$ & & 0062 \\
\hline П10 & g/ul & Group il & $\mathrm{F}$ & $12.68 \pm 1.01$ & 1.950 & 0.005 \\
\hline & & Groun III & $\mathrm{M}$ & $13.62 \pm 1.14$ & 3715 & 0001 \\
\hline & & Group in & $\mathrm{F}$ & $12.03 \pm 0.92$ & & \\
\hline
\end{tabular}

In the present study, the level of FPG in the group II was significantly increment in comparison with I and III groups, these results are in agreement with the various studies, which have suggested that elevated blood glucose is the driving force for the advancement of DN. Hyperglycemia-stimulate promotes mitochondrial ROS generation as a consequence of glucose autoxidation metabolism and the formation of AGEs, ROS comprise the real source of intracellular ROS that outcome in the oxidative harm of proteins, lipid, and DNA, at last leading to apoptosis and kidney damage. ${ }^{[11]} \mathrm{DN}$ is considered as an inflammatory disease described by leukocyte infiltration at each phase of renal contribution. [12] The high levels of U. Mic and ACR in diabetic patients with microalbuminuria group demonstrating that Microalbuminuria an early marker of DN, the elevated levels of urinary albumin excretion may represent a more generalized vascular harm than kidney microangiopathy damage alone. [13] Microalbuminuria is linked with numerous of the disorders found in the insulin resistance disorder, including obesity and endothelial dysfunction in addition to type 2 diabetes. ${ }^{[14]}$ 

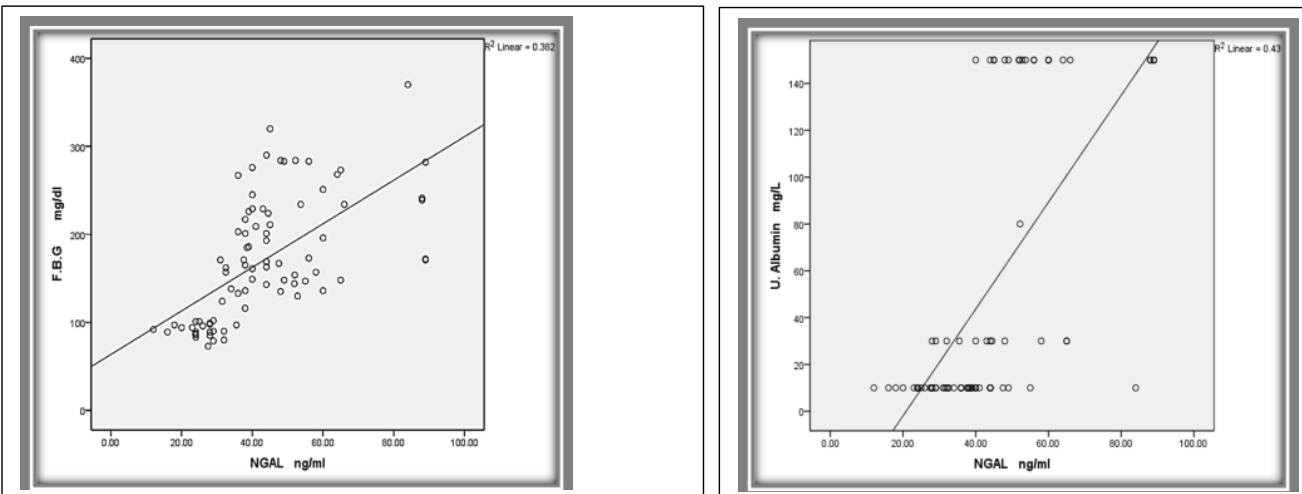

Fig.(2): The association between plasma NGAL with FPG and U. Albumin.

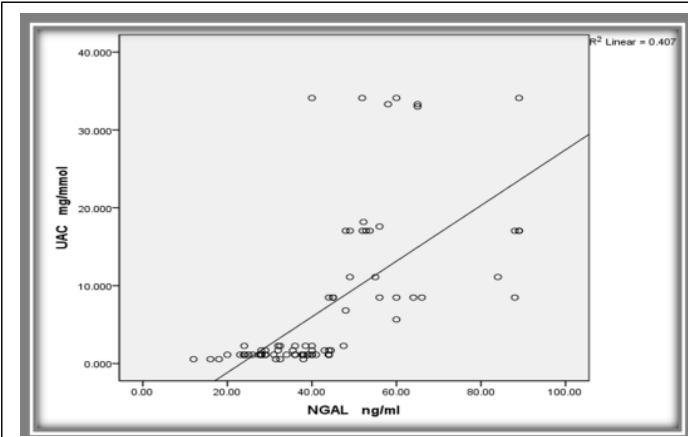

Fig.(3): The association between plasma NGAL with UAC.
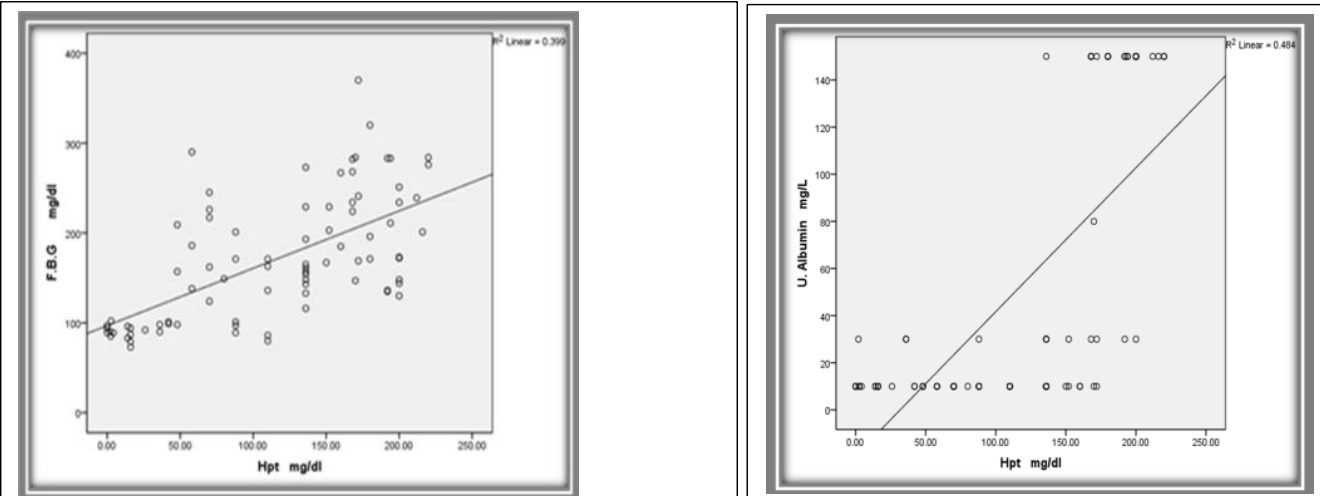

Fig.(4): The association between plasma HPt with FPG and U. Albumin. 

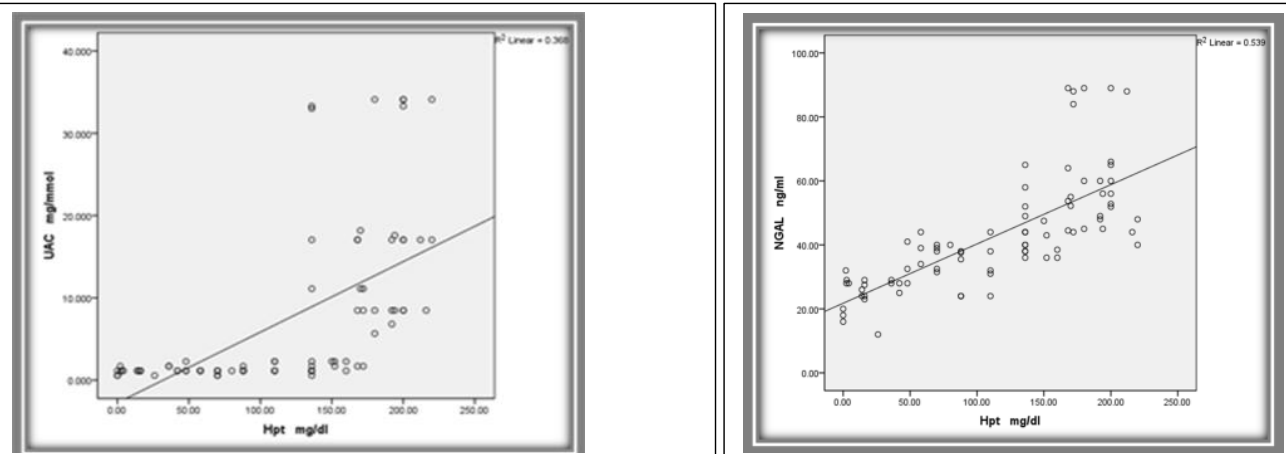

Fig.(5): The association between plasma HPt with UAC and NGAL.

Plasma NGAL was significantly higher in micro-normoalbuminuria diabetic groups compared to the control group. Recommending that lipocalin-2 might be an independent risk factor for hyperglycemia and insulin resistance in human. Several previous studies have proposed lipocalin-2 to be an intense -stage protein that can be initiated by a variety of inflammatory stimuli ${ }^{[15,16]}$ in type 2 diabetic patients, patients with microalbuminuria had higher plasma NGAL levels. This finding accept the hypothesis of an extensive increment in extra-renal creation of NGAL in diabetic patient eventually reduced clearance of NGAL because of decrease in renal function could also contribute to the high plasma NGAL levels particularly in the macroalbuminuria patients ${ }^{[17]}$ NGAL plays a renoprotective part through upgrading tubule cell increase in kidney damage, particularly in ischemia-reperfusion harm, ${ }^{118]}$ an expanding body of evidence demonstrates that NGAL associates strongly with the kidney. NGAL can prompt the construction of renal epithelia by motivating the transformation of mesenchymal cells into proximal tubule epithelia, this is because NGAL can function as an iron-transporting protein to convey $\mathrm{Fe}^{2+}$ by forming a complex with iron-binding siderophores (NGAL: siderophore: $\mathrm{Fe}^{2+}$ ) and $\mathrm{Fe}$ is essential for cell development and improvement. ${ }^{[19,18]}$ NGAL binding with large affinity to bacterial, iron binding proteins named siderophores. Iron, an especially ferrous shape is essential to bacteria for their development. In the case, very low levels of free iron in the body make it a fundamental nutrient required by bacterial cells. ${ }^{[20]}$

Additionally, plasma NGAL a strong positively associated with FPG, U. Mic, and ACR. The Plasma NGAL level was elevated in diabetic patients with microalbuminuria compared to controls, indicating that tubular harm happens early and possibly before albumin secretion in patients with DN. ${ }^{[21]} \mathrm{HPt}$ a major increment in oxidative stress and oxidative tissue harm, particularly in the kidney in human. Free $\mathrm{Hb}$ in the circulation passes through the renal damage, encourages the generation of free radicals inside the kidney and glomerular filter and stimulates the generation of free radicals inside the kidney after the demolition of erythrocytes. ${ }^{[22]}$ The quantity of hemoglobin penetrating blood vessel walls might be distinctly elevated in patients with DM. HPt can quickly bind free intravascular hemoglobin released into the circulation and stop hemoglobin-driven oxidation responses. ${ }^{[23]}$ The outcomes of this study shows that a strong positive correlation was observed between plasma $\mathrm{HPt}$ concentration and FBG, Dia. BP \& Sys. BP, intensive blood glucose levels near to the normal range has been demonstrated contributor to oxidative stress as accordingly elevated of HPt phenotype. Additional, expanded plasma HPt levels are real indications of adiposity in the individual. HPt is an intense phase protein that acts as an antioxidant by virtue of its ability to associate free $\mathrm{Hb}$ and avoid heme-iron interceded oxidation. ${ }^{[24]} \mathrm{Hb}$ is released into the 
circulation, it binds immediately to $\mathrm{HPt}$ to form a HPt- $\mathrm{Hb}$ complex that is rapidly extracted predominately by the macrophage CD163 scavenger receptor expressed on Kupfer cells in the liver. ${ }^{[25]}$ There are expansive variation in body synthesis between man and women due sex steroid hormones levels between genders, the distinction of sex in mean hemoglobin level of vein is considered to be the important reason of the stimulatory impact of androgen in man`s bone marrow, in addition to inhibiting influence of estrogen on woman's bone marrow. ${ }^{[26]}$ The mean red cell mass levels in the male are more than female due increased erythropoiesis by the impact of androgen in the male or the periodic loss of blood in female. ${ }^{[27]}$

\section{Conclusion}

In conclusion, there were a strong positive correlation between plasma NGAL \& HPt with FPG, U.albumin and ACR. The outcomes of the present study showed that plasma concentration of NGAL and $\mathrm{HPt}$ were significantly higher in patients with normomicroalbuminuria diabetic groups compared to a healthy control group, indicating that plasma NGAL \& HPt may be good prognostic factors for renal dysfunction and the development of incipient nephropathy.

\section{References}

[1] Tonelli M, Muntner P, Lloyd A, et al., "Risk of coronary events in people with chronic kidney disease compared with those with diabetes: a population-level cohort study", Lancet, 380 (9844), 807-14, 2012.

[2] Shaw JE, Sicree RA and Zimmet PZ., "Global estimates of the prevalence of diabetes for 2010 and 2030", Diabetes Res Clin Pract, 87 ( '),4-14, 2010.

[3] Moresco RN, Sangoi MB, De Carvalho JA, et al., "Diabetic nephropathy: traditional to proteomic markers", Clin Chim Acta, 5 (421), 17-30, 2013.

[4] Chae HW, Shin JI, Kwon AR, et al., "Spot urine albumin to creatinine ratio and serum cystatin $\mathrm{C}$ are effective for detection of diabetic nephropathy in childhood diabetic patients”, J Korean Med Sci, 27 (7), 784-7, 2012.
[5] Nielsen SE, Reinhard H, Zdunek D, et al., "Tubular markers are associated with Decline in kidney function in proteinuric type 2 diabetic patients", Diabetes Res Clin Pract; 97(1), 71-6, 2012.

[6] Bennett M, Dent CL, Ma Q, et al., "Urine NGAL predicts severity of acute kidney injury after cardiac surgery: a prospective study", Clin J Am Soc Nephrol, 3 (3), 66573, 2008.

[7] Papadopoulou-Marketou N, Skevaki C, Kosteria I, et al., "NGAL and cystatin C: two possible early markers of diabetic nephropathy in young patients with type1 diabetes mellitus: one year follow up", Hormones (Athens), 14(2), 232-40, 2015.

[8] Mahfouz MH, Assiri AM, and Mukhtar $\mathrm{MH}$,. "Assessment of neutrophil gelatinaseassociated Lipocalin (NGAL) and retinolbinding protein 4 (RBP4) in type 2 diabetic patients with nephropathy". Biomarker Insights, 11(1), 31-40, (2016).

[9] Levy AP, Asleh R, Blum S, et al., "Haptoglobin: Basic and clinical Aspects", Antioxidant and redox signaling, 12 (2), 293-304, 2010.

[10] Nafisa MO, Hind AG, and Atif AE, "Study of Haptoglobin phenotypes in Sudanese Diabetic patients", Amrican Jurnal of microbiological Research, 4 (2), 61-63, 2016.

[11] Rohilla A, Tiwari SK, Rohilla S, et al, "Diabetic Nephropathy: Pathogenesis, Prevention and Treatment", Euro. J. Exp. Bio, 1(4), 72-80, 2011.

[12] Wolf $G$ and Ruster $C$,. "The role of chemokines and chemokine receptors in diabetic nephropathy", Front Biosci, 13 (1), 944-955, 2008.

[13] Battisti WP, Palmisano J and Keane WE, "Dyslipidemia in patients with type 2 diabetes: Relationships between lipids, kidney disease and cardiovascular disease", Clin Chem Lab Med, 41 (9), 1174-81, 2003.

[14] De Gaudio AR, Adembri C, Grechi S, et $a l$,. "Microalbuminuria as an early index of impairment of glomerular permeability in postoperative septic patients", Intensive Care Med, 26(9), 1364-68, 2000. 
[15] Lin Y, Rajala MW, Berger JP, et al,. "Hyperglycemia-induced production of acute phase reactants in adipose tissue", J Biol Chem, 276 (45), 42077-42083, 2001.

[16] Cowland JB, Muta T and Borregaard N,. "IL-1-specific upregulation of neutrophil gelatinase-associated lipocalin is controlled by IkappaB-zet", J Immunol, 176 (9), 5559-5566, 2006.

[17] Bolignano D, Lacquaniti D, Coppolino G, et al,. "Neutrophil gelatinase-associated lipocalin as an early biomarker of nephropathy in diabetic patients", Kidney Blood Press Res, 32 (2), 91-98, 2009.

[18] Mori K, Lee HT, Foster K, et al,. "Endocytic delivery of lipocalinSiderophore-iron complex rescues the kidney from ischemia-reperfusion injury", $J$ Clin Inres, 115 (3), 610-621, 2005.

[19] Yang J, Goetz D, Wang W, et al,. “An iron delivery pathway mediated by a Lipocalin", Mol Cell, 10 (5), 1045-1056, 2002.

[20] Nairz M, Theurl I, Schroll A, et al,. "Absence of functional Hfe protects mice from invasive Salmonella enterica serovar Typhimurium infection via induction of lipocalin-2", Blood, 114 (17), 3642-3651, 2009.

[21] Yang YH, He X J, Chen SR, et al,. "Changes of serum and urine neutrophil gelatinase-associated lipocalin in type-2 diabetic patients with nephropathy: One year observational follow-up study", Endocrine, 36 (1), 45-51, 2009.

[22] Langlois MR and Delanghe JR,. "Biological and Clinical significance of Haptoglobin polymorphisms in humans", Clin Chem, 42(10), 1589-1600, 1996.

[23] Asleh R, Marsh S, Binah O, et al,. "Genetically determined heterogeneity in hemoglobin scavenging and susceptibility to diabetic cardiovascular disease", Circ Res 92(11), 1193-1200, 2003.

[24] Makuc J, Petrovič D, "A review of oxidative stress related genes and new antioxidant therapy in diabetic nephropathy", Cardiovascular and Hematological Agents in Medicinal Chemistry, 9 (4), 253-61, 2011.

[25] Vardi M, Blum S, and Levy AP,. "Haptoglobin genotype and cardiovascular outcomes in diabetes mellitus-natural history of the disease and the effect of vitamin e treatment. Metaanalysis of the medical literature", European Journal of Internal Medicine, 23 (7), 628-32, 2012.

[26] Murphy WG,. "the sex difference in haemoglobin levels in adults-mechanisms, causes, and consequences", Blood Rev, 28 (2), 41-47, 2014.

[27] Tong E, Murphy WG, Kinsella A, et al, "Capillary and venous haemoglobin levels in blood donors: a 42-month study of 36,258 paired samples", Vox Sang, 98 (4), 547-553, 2010. 